\title{
Consequentialism and Respect: Two Strategies for Justifying Act Utilitarianism
}

\author{
Ben Eggleston* \\ University of Kansas \\ ${ }^{\star}$ Corresponding author. Email: eggleston@ku.edu
}

(Received 1 August 2018; revised 31 January 2019; accepted 1 February 2019)

\begin{abstract}
Most arguments in support of act utilitarianism are elaborations of one of two basic strategies. One is the consequentialist strategy. This strategy relies on the consequentialist premise that an act is right if and only if it produces the best possible consequences and the welfarist premise that the value of a state of affairs is entirely determined by its overall amount of well-being. The other strategy is based on the idea of treating individuals respectfully and resolving conflicts among individuals in whatever way best conforms to that idea. Although both of these strategies can be used to argue for the principle of act utilitarianism, they are significantly different from each other, and these differences cause them to have different strengths and weaknesses. It emerges that which argumentative strategy is chosen by a proponent of act utilitarianism has a large impact on which virtues her view has and which objections it is vulnerable to.
\end{abstract}

\section{Introduction}

Act utilitarianism is one of the most heavily debated views in moral philosophy, and the arguments that can be given in support of it are remarkably diverse. But most of them are elaborations of one of two basic strategies. These two strategies are significantly different from each other, and these differences cause them to have different strengths and weaknesses. In this article, I describe the two strategies and explore their advantages and disadvantages. It emerges that which argumentative strategy is chosen by a proponent of act utilitarianism has a large impact on which virtues her view has and which objections it is vulnerable to.

Any given theorist's version of act utilitarianism would normally consist of a criterion of rightness along with one or more arguments in support of it. Here, because I want to look at the arguments separately, I will consider act utilitarianism to be simply a criterion of rightness - namely, the following:

act utilitarianism: An act is right if and only if it results in at least as much overall well-being as any act the agent could have performed. 
Some theorists who maintain act utilitarianism (so defined) also hold a particular theory of well-being. They can then assert a more specific view, such as one of the following:

hedonistic act utilitarianism: An act is right if and only if it results in at least as much net pleasure (pleasure minus pain) as any act the agent could have performed.

preference-satisfaction act utilitarianism: An act is right if and only if it results in at least as much overall preference satisfaction as any act the agent could have performed.

Such additional specificity, if achieved without an offsetting loss of plausibility, is sometimes advantageous in works of theory articulation and advocacy. But here, when I refer to act utilitarianism, I will be referring simply to the statement given near the beginning of this paragraph, without any particular conception of well-being in mind.

In the next two sections, I will present the two argumentative strategies this article examines. One of them is consequentialist and the other is based on respect. ${ }^{1}$ I do not take these strategies to encompass (even in stylized form) all arguments for act utilitarianism, nor do I take the use of either of these strategies to preclude the use of other methods of justification, such as reflective equilibrium. But I think these strategies are sufficiently important, and differ in sufficiently interesting ways, to be worth the examination I undertake here. (They are even more worthy of study if they are relevant to arguments for other forms of utilitarianism, such as rule utilitarianism and virtue utilitarianism, though I take no stand on that here.)

For ease of exposition, I will put the two strategies in the mouths of two moralphilosophical characters, whom I will call the Consequentialist and the Respecter. After presenting the two strategies, I will briefly note some contrasts between them. In the remaining sections of this article, I will explore ways in which either the Consequentialist or the Respecter is in an advantaged position in regard to a potential virtue of, or objection to, act utilitarianism.

\section{The Consequentialist}

The first strategy for justifying act utilitarianism is that of the Consequentialist. The Consequentialist, I should emphasize at the outset, is a character I am defining in terms of a specific set of propositions. I don't intend for the Consequentialist's view to match any particular published consequentialist theory, or to be a good dictionary or encyclopaedia account of consequentialism. Nor it is necessary, for my purposes, that the Consequentialist's argument seem to contain any notable innovation. In fact,

\footnotetext{
${ }^{1}$ The next three sections draw heavily from Ben Eggleston, 'Act Utilitarianism', The Cambridge Companion to Utilitarianism, ed. Ben Eggleston and Dale E. Miller (Cambridge, 2014), pp. 125-45, at 132-5. As I indicate there, my division of the arguments into these two kinds, along with some of the examples I cite, is indebted to Will Kymlicka, Contemporary Political Philosophy: An Introduction, 2nd edn. (Oxford, 2002), pp. 32-7. (I cannot warrant, however, that he would agree with my elaborations of the two strategies or my comparative assessment of them.) These two kinds of arguments are also noted briefly in Roger Crisp, 'Utilitarianism and the Life of Virtue', The Philosophical Quarterly 42 (1992), pp. 139-60, at 139-40.
} 
this argument is quite familiar. The value of this view, for my purposes, depends not on whether it is novel or accurate (the latter concept is not even applicable), but on whether it is plausible enough, as a justification of act utilitarianism, for its implications and other characteristics to be worth exploring.

The Consequentialist starts by focusing on states of affairs, and he holds that some states of affairs are better than others. He then makes this idea more determinate by embracing two additional theses. One of these holds that only well-being contributes to the goodness of a state of affairs:

welfarism: The value of a state of affairs is positively related to, and determined by nothing other than, the well-being it contains. ${ }^{2}$

Now, this thesis is compatible with several mutually exclusive theses about how the value of a state of affairs is determined by the valuable things (such as well-being) it contains. One of these is concerned with equality, holding that the value of a state of affairs is positively related to, and determined by nothing other than, how equally the valuable things (whatever they may be) are distributed in that state of affairs. ${ }^{3}$ Another is concerned with minimizing disadvantage, holding that the value of a state of affairs is positively related to, and determined by nothing other than, the quantity of valuable things that is enjoyed by the individual who has the smallest quantity of them. ${ }^{4} \mathrm{~A}$ third is concerned with maximizing the total quantity of what is valuable. This is the thesis that the Consequentialist endorses as part of his strategy for justifying act utilitarianism:

sum-ranking: The value of a state of affairs is positively related to, and determined by nothing other than, the total quantity of the value it contains. ${ }^{5}$

Combining the theses of welfarism and sum-ranking yields the view that the value of a state of affairs is positively related to, and determined by nothing other than, the total quantity of well-being it contains. This view is, obviously, very close to act utilitarianism.

But this view is only about states of affairs, not acts. So the Consequentialist embraces one further thesis, about the way the morality of any given act depends on its consequences:

act consequentialism: An act is right if and only if its consequences are at least as good as the consequences of any act the agent could have performed.

\footnotetext{
${ }^{2}$ For a thorough discussion of welfarism and an influential critique of it, particularly with a view to its use in utilitarianism, see Amartya Sen, 'Utilitarianism and Welfarism', The Journal of Philosophy 76 (1979), pp. 463-89, esp. pp. 471-89.

${ }^{3}$ Such a view is discussed at length in Ronald Dworkin, 'What Is Equality? Part I: Equality of Welfare', Philosophy and Public Affairs 10 (1981), pp. 185-246.

${ }^{4}$ This thought is similar to John Rawls's difference principle (John Rawls, A Theory of Justice (Cambridge, MA, 1971), pp. 75-83). This thought is developed differently in prioritarianism, a cousin of utilitarianism for which the most-discussed source is Derek Parfit, 'Equality and Priority', Ratio 10 (1997), pp. 202-21. See, as well, Dennis McKerlie, 'Equality and Priority', Utilitas 6 (1994), pp. 25-42.

${ }^{5}$ See Sen, 'Utilitarianism and Welfarism', pp. 468-71. Also see the discussion of sum-ranking welfarism in Krister Bykvist, 'Utilitarianism in the Twentieth Century', The Cambridge Companion to Utilitarianism, ed. Ben Eggleston and Dale E. Miller (Cambridge, 2014), pp. 103-24, at 106-13.
} 
This thesis, combined with welfarism and sum-ranking, completes the Consequentialist's justification for act utilitarianism. This justification is, then, a sum-ranking welfarist act-consequentialist one.

Arguments similar to this one are suggested by three of the most influential writers in the utilitarian tradition: John Stuart Mill, Henry Sidgwick and G. E. Moore. First, Mill writes the following:

That the morality of actions depends on the consequences which they tend to produce, is the doctrine of rational persons of all schools; that the good or evil of those consequences is measured solely by pleasure or pain is all of the doctrine of the school of utility, which is peculiar to it. ${ }^{6}$

Sidgwick, in turn, famously suggests that the moral point of view is 'the point of view (if I may say so) of the Universe' and he reports that 'it is evident to me that as a rational being I am bound to aim at good generally ... not merely at a particular part of it'. Such cosmological aspirations also feature in Moore's Principia Ethica. There Moore focuses on 'the greatest possible amount of good in the Universe' and writes that 'the primary and peculiar business of Ethics' is 'the determination [of] what things have intrinsic value and in what degrees'. ${ }^{8}$ These remarks demonstrate his taking states of affairs to be, as he says, primary. He also commits himself to the thesis of act consequentialism with his statement that 'the assertion "I am morally bound to perform this action" is identical with the assertion "This action will produce the greatest possible amount of good in the Universe"'?

The Consequentialist's strategy for arguing for act utilitarianism enjoys some prominence today. This is probably due, at least in part, to its neat factoring of act utilitarianism into distinct components, ${ }^{10}$ which facilitates exposition, analysis and

\footnotetext{
'John Stuart Mill, 'Bentham', The Collected Works of John Stuart Mill, ed. J. M. Robson, 33 vols (Toronto, 1963-91), vol. X, pp. 75-115, at 111. Mill may or may not have been an act utilitarian; for discussion, see David Brink, 'Mill's Moral and Political Philosophy', The Stanford Encyclopedia of Philosophy (Winter 2018 edn.), ed. Edward N. Zalta, <https://plato.stanford.edu/archives/win2018/entries/mill-moralpolitical/>, esp. sect. 2: 'Mill's Utilitarianism'. See also Ben Eggleston, 'Mill's Moral Standard', A Companion to Mill, ed. Christopher Macleod and Dale E. Miller (Malden, 2014), pp. 358-73.

${ }^{7}$ Henry Sidgwick, The Methods of Ethics, 7th edn. (London, 1907), p. 382.

${ }^{8}$ G. E. Moore, Principia Ethica, revised edn., ed. Thomas Baldwin (Cambridge, 1993), pp. 197 and 78. Moore seems not to have been an act utilitarian, as defined above, since he seems not to have held that well-being is the only good. See Thomas Hurka, 'Moore's Moral Philosophy', The Stanford Encyclopedia of Philosophy (Fall 2015 edn.), ed. Edward N. Zalta, <https://plato.stanford.edu/archives/fall2015/entries/ moore-moral/>, esp. sect. 4: 'The Ideal'. But he was nonetheless a writer in the utilitarian tradition, and he is often given the courtesy of inclusion via the term 'ideal utilitarianism'. See Julia Driver, 'The History of Utilitarianism', The Stanford Encyclopedia of Philosophy (Winter 2014 edn.), ed. Edward N. Zalta, <https://plato.stanford.edu/archives/win2014/entries/utilitarianism-history/>, esp. sect. 4: 'Ideal Utilitarianism'.

${ }^{9}$ Moore, Principia Ethica, p. 197.

${ }^{10}$ See, for example, Amartya Sen and Bernard Williams, 'Introduction', Utilitarianism and Beyond, ed. Sen and Williams (Cambridge, 1982), pp. 1-21, at 3-4; and the excellent overview in Geoffrey Scarre, Utilitarianism (London, 1996), pp. 4-24. For similar textbook passages, see James Rachels and Stuart Rachels, The Elements of Moral Philosophy, 9th edn. (New York, 2019), p. 118; Russ Shafer-Landau, The Fundamentals of Ethics, 4th edn. (New York, 2018), pp. 120-4; and Mark Timmons, Moral Theory: An Introduction, 2nd edn. (Lanham, 2013), pp. 112-14.
} 
criticism. Another probable reason is the rise, in recent decades, of consequentialism itself as a focal point within the discipline of moral philosophy. ${ }^{11}$

\section{The Respecter}

The second strategy for justifying act utilitarianism is that of the Respecter. Like the Consequentialist, the Respecter is a character I am defining in terms of a specific set of propositions. I don't suggest that her view is a neutral, agenda-free analysis and articulation of the concept of respect. Rather, as will become apparent shortly, it is a frank and overt attempt to leverage the concept of respect into justifying act utilitarianism, even though they are often placed in opposition to each other. Respect is a touchstone for rivals of utilitarians (such as Kantians), and most such theorists would probably react to the Respecter's deployment of their favoured concept with 'thanks, but no thanks'. ${ }^{12}$ Like the Consequentialist's argument, however, the Respecter's argument does not need to be incontestable; it just needs to be plausible enough to be worth the further examination that I pursue below.

The Respecter focuses on individuals and regards morality as primarily concerned with conflicts that arise between and among individuals. Some such conflicts have obviously correct resolutions. For example, if a builder has met all of the requirements for a construction permit, a corrupt bureaucrat might plan to withhold the permit unless the builder pays him a bribe of $\$ 1$ million while the builder would want to receive the permit without having to pay the bribe. Or a zoologist might think it would be interesting to engage in the slow dissection of a dog or cat without the use of anaesthesia while the dog or cat would be better off left alone. But some such conflicts are not so one-sided. For example, some commuters might want their city to widen a particular road while nearby residents might prefer the status quo. The Respecter holds that deciding such conflicts morally means deciding them in a way that best conforms to the idea of treating individuals respectfully.

In saying that the Respecter regards morality as primarily concerned with conflicts that arise between and among individuals, I do not mean that the Respecter regards morality as limited to isolated situations in which one individual or group instigates a specific transaction or project that another individual or group opposes. The Respecter also considers morality to be concerned with topics such as climate change, immigration, poverty relief, social services, factory farming, the financing of political campaigns, abortion, euthanasia, and so on. But the Respecter is keenly aware that different individuals stand to be differently affected by different decisions on these issues, and she holds that addressing these issues morally is a matter of treating the individuals involved respectfully, even if there are billions of them.

Of course, the notion of treating individuals respectfully is, by itself, a highly indeterminate guide to deciding conflicts, and thus the Respecter's recommended resolution

\footnotetext{
${ }^{11}$ Early visible examples of this trend include Samuel Sheffler, The Rejection of Consequentialism: A Philosophical Investigation of the Considerations Underlying Rival Moral Conceptions (Oxford, 1982); Peter Railton, 'Alienation, Consequentialism, and the Demands of Morality', Philosophy and Public Affairs 13 (1984), pp. 134-71; and Philip Pettit, 'Consequentialism', A Companion to Ethics, ed. Peter Singer (Oxford, 1991), pp. 230-40.

${ }^{12}$ Peter Railton reflects on the disparate notions of respect that he sees as underlying deontology and consequentialism and concludes "Which notion takes "respect for persons" more seriously? There may be no non-question-begging answer' (Railton, 'Alienation, Consequentialism, and the Demands of Morality', p. 163 n. 32).
} 
of any conflict will depend heavily on her conception of that notion. This brings me to the next principle that I need to stipulate as part of the Respecter's view:

respect and interests: An individual is treated respectfully in the making of a decision that affects him or her if and only if, and to the extent that, the decisionmaking aims at the protection and promotion of his or her interests.

This principle immediately raises the question of what the Respecter's conception of an individual's interests is, and I shall give the Respecter's answer to that question shortly. Independent of that, however, just the ordinary, untheorized concept of an individual's interests is probably enough to rule out certain ideas that might come to mind, such as the Kantian idea that treating an individual respectfully always requires abstaining from treating him or her as a mere means. According to the Respecter, this exceptionless edict does not follow from the notion of treating an individual respectfully, because an individual's interests include far more than this one concern. Of course, this leaves it open to the Respecter to acknowledge that treating an individual as a mere means often detracts significantly from the protection and promotion of his or her interests.

The ordinary idea of an individual's interests can go only so far towards fleshing out the meaning of the principle of respect and interests. Further clarity requires, as I acknowledged above, attributing to the Respecter a specific conception of an individual's interests. That conception is stated in the following principle:

the well-being conception of interests: An individual's interests are constituted by his or her well-being. An individual's interests are advanced by benefits to him or her, and are impeded by harms to him or her.

The motivation for attributing this principle to the Respecter is evident: in order for the Respecter's concern with treating individuals respectfully to end up being an argument for act utilitarianism, that concern needs to end up focusing on their well-being.

The components of the Respecter's view stated so far pertain to the respectful treatment of a single individual. Let us turn now to the situations the Respecter thinks of as the principal concern of morality - conflicts between and among multiple individuals. This raises a structural issue that the Respecter needs to have a view about. Suppose, in the road-widening scenario mentioned above, each resident's well-being stands to be affected more than each commuter's does: i.e. if the road is widened, each resident will be harmed more than each commuter will be benefited. How, then, are the conflicting interests to be weighed? One approach the Respecter could take is to say that the conflict should be decided with reference to whichever individual stands to have his or her well-being affected the most. On this approach, the numbers of commuters and residents do not matter; instead, we are to find the individual who stands to be affected most strongly and make the corresponding decision. A second approach is to say that the numbers do matter:

respect and additivity: Treating multiple individuals respectfully in decisionmaking requires regarding the well-being gains and losses that each of them stands to incur, as a result of any given act being chosen, as adding to or subtracting from the overall moral quality of that act. 
On this view, the numbers of individuals on the different sides of an issue matter; a large number of small impacts on well-being can outweigh a small number of large impacts on well-being. Since I have said that the Respecter's line of thought commits her to act utilitarianism, it is obvious that I define her as opting for respect and additivity rather than the previous approach. ${ }^{13}$

One final issue remains to be addressed in order to complete the characterization of the Respecter. The principles stated so far do not rule out the possibility that in the moral assessment of an act, that act's impacts on some individuals' well-being might be regarded as more important than its impacts on other individuals' well-being. The principle of respect and additivity requires that each individual count in the moral assessment of any given act, but it allows that some individuals might count more than others, i.e. that their possible well-being gains and losses might be given extra weight in the addition and subtraction. The extra weight might be attributed in an agent-neutral way (for example, extra weight for individuals who are disadvantaged relative to others, or who are virtuous) or in an agent-relative way (for example, extra weight for the agent and individuals with whom he or she has close relationships). Of course, just the bare statement of this possibility calls to mind the contrary principle that the Respecter must endorse in order to be an act utilitarian:

respect and equality: Treating multiple individuals respectfully in decision-making requires regarding all of them as equally important in the moral assessment of any given act.

If all of them are regarded as equally important, then no one gets extra weight, and a well-being impact of a given size makes the same difference - the same addition or subtraction - regardless of which individual stands to incur it.

These four principles - respect and interests, the well-being conception of interests, respect and additivity, and respect and equality - complete the characterization of the Respecter. The first three of these are controversial, to be sure. But my present business is just to describe the Respecter's view; later sections of this article will examine its strengths and weaknesses vis-à-vis the Consequentialist's. What we can say now, with the four principles stated, is that the Respecter holds that deciding conflicts morally means deciding them in accordance with the largest available net increase in the wellbeing of the individuals affected by the decision.

Now, it is easy to establish that this criterion is mathematically equivalent to the actutilitarian criterion of maximizing overall well-being. Given some overall level of wellbeing before a conflict is decided, if the conflict is decided in accordance with the largest available net increase in well-being, then the resulting overall level of well-being will be as large as possible. (In short, given some starting amount, choosing the largest increase will result in the largest total.) Thus, the Respecter's reasoning about how conflicts should be decided ends up being an argument for act utilitarianism.

\footnotetext{
${ }^{13}$ On the topic of additivity and other approaches, seminal works include John M. Taurek, 'Should the Numbers Count?', Philosophy and Public Affairs 6 (1977), pp. 293-316; and Derek Parfit, 'Innumerate Ethics', Philosophy and Public Affairs 7 (1978), pp. 285-301. Recent articles attending thoroughly to the pertinent literature include Ben Saunders, 'A Defence of Weighted Lotteries in Life Saving Cases', Ethical Theory and Moral Practice 12 (2009), pp. 279-90; and Yishai Cohen, 'Don't Count on Taurek: Vindicating the Case for the Numbers Counting', Res Publica 20 (2014), pp. 245-61.
} 
Remarks suggestive of this strategy are found in the works of many historical and recent proponents of utilitarianism. In many cases, though, 'suggestive' is all they can be called. I certainly do not claim that any of these authors would endorse everything I attribute to the Respecter. But, as I emphasized in regard to the Consequentialist, such historical roots are unnecessary; I mention these authors merely to illustrate some lines of thought possibly kindred to the Respecter's.

In Jeremy Bentham's massive body of work, one of the most frequently quoted remarks - the one Mill called 'Bentham's dictum' ${ }^{\text {'14 }}$ - is that 'every individual in the country tells for one; no individual for more than one'. ${ }^{15}$ Mill himself, though quoted above in affinity with the Consequentialist, arguably also endeavours to co-opt a perspective akin to the Respecter's when he writes: 'In the golden rule of Jesus of Nazareth, we read the complete spirit of the ethics of utility. To do as one would be done by, and to love one's neighbour as oneself, constitute the ideal perfection of utilitarian morality.16 This, I submit, can be construed as Respecter-ish in so far as the golden rule is seen as called into service to address conflicts between individuals' interests, and is interpreted as a proposal for deciding such conflicts in terms of impacts on individuals' well-being.

The Respecter's orientation of comparing the magnitudes of impacts on individuals' well-being is also present in the work of several recent utilitarian theorists. For example, a key premise in one of John Harsanyi's defences of act utilitarianism is that 'a social welfare function ought to be based ... on the utility functions (subjective preferences) of all individuals, representing a kind of "fair compromise" among them'. ${ }^{17}$ R. M. Hare, in turn, writes that he argues for act utilitarianism 'by a Kantian route' - a route based on the logic of moral argument (often as applied to conflicts between people's preferences) rather than, say, a Sidgwickian intuition about a duty to promote the good. He says that by this route 'We are led to give weight to the preferences of all the affected parties ... in proportion to their strengths'. ${ }^{18}$ Similarly, Ken Binmore presents an argument for act utilitarianism based on 'do-as-you-would-be-done-by principles' and 'empathetic preferences'. ${ }^{19}$

Finally, much of Peter Singer's argument for act utilitarianism in his Practical Ethics aligns with the Respecter's argument. Singer credits Hare with influencing the 'foundations' of his view ${ }^{20}$ and he leads the reader to his view by way of the golden rule, Bentham's dictum and Hare's emphasis on universalizability. ${ }^{21} \mathrm{He}$ writes that this

\footnotetext{
${ }^{14}$ John Stuart Mill, Utilitarianism, The Collected Works of John Stuart Mill, ed. J. M. Robson, 33 vols. (Toronto, 1963-91), vol. X, pp. 203-59, at 257.

${ }^{15}$ Jeremy Bentham, Rationale of Judicial Evidence, The Works of Jeremy Bentham, ed. John Bowring, vols. VI-VII (Edinburgh, 1838-43), vol. VII, p. 334.

${ }^{16}$ Mill, Utilitarianism, p. 218.

${ }^{17}$ John C. Harsanyi, 'Cardinal Welfare, Individualistic Ethics, and Interpersonal Comparisons of Utility', The Journal of Political Economy 63 (1955), pp. 309-21, at 315. Also see his 'Morality and the Theory of Rational Behaviour', Utilitarianism and Beyond, ed. Amartya Sen and Bernard Williams (Cambridge, 1982), pp. 39-62, at 44-8.

${ }^{18}$ R. M. Hare, 'The Structure of Ethics and Morals', Essays in Ethical Theory (Oxford, 1989), pp. 175-90, at 187. Also see his Sorting out Ethics (Oxford, 1997), p. 145, where he echoes Bentham's dictum almost verbatim. Hare explores the affinities between his approach and Kant's in his 'Could Kant Have Been a Utilitarian?' (Sorting Out Ethics, ch. 8).

${ }^{19}$ Ken Binmore, 'A Theory of Political Legitimacy', Economics, Values, and Organization, ed. Avner Ben-Ner and Louis Putterman (Cambridge, 1998), pp. 101-32, at 112 and 113.

${ }^{20}$ Peter Singer, Practical Ethics, 3rd edn. (Cambridge, 2011), p. xii.

${ }^{21}$ Singer, Practical Ethics, p. 10.
} 
cluster of ideas - requiring that one weigh other people's preferences alongside one's own - quickly leads to act utilitarianism: 'we very swiftly arrive at an initially preference utilitarian position once we apply the universal aspect of ethics to simple, pre-ethical decision making. The preference utilitarian position is ... a first base that we reach by universalizing self-interested decision making. ${ }^{22}$ Maximizing the good is not part of this line of reasoning. Singer is, of course, a noted Sidgwick scholar, ${ }^{23}$ and one might assume that a Sidgwickian defence of act utilitarianism would figure heavily in his own thinking. In fact, however, this is not the case, at least not in Practical Ethics. Thorough exegesis would be excessive here, but just as an illustrative detail, note that Sidgwick's idea of 'the point of view of the universe' does not appear until the antepenultimate paragraph of Practical Ethics, ${ }^{24}$ and then only as a device for giving meaning and purpose to one's life - something a person might choose to pursue as 'more significant' than 'collecting stamps or following their favourite football team'. ${ }^{25}$ Singer describes Sidgwick's perspective admiringly, but treats it as optional rather than foundational.

\section{Contrasts}

The Consequentialist and the Respecter, though both act utilitarians, differ in significant ways. To begin, speaking very roughly, one might say that the Consequentialist's derivation of act utilitarianism is 'top down', while the Respecter arrives at act utilitarianism in a more 'bottom up' fashion.

We can spell out this contrast in a little more detail. The Consequentialist, by initially focusing on states of affairs, does not initially focus on individuals (and their well-being). Individuals come in somewhat later, and subordinately, as means to the achievement of valuable states of affairs. If the Consequentialist did not embrace welfarism and, instead, had some other principle for what determines the value of a state of affairs, then he might not hold that morality has anything to do with individuals at all.

In contrast, the Respecter pays attention to individuals before anything else. In any situation, she is concerned with treating the individuals respectfully and opts for the decision that is most supported, as she sees it, by the interests of all of those individuals. For her, the concept of maximization comes in fairly late in the proceedings, as an implication rather than a premise. To see this, consider two intermediate links in the chain of reasoning that leads to the Respecter's being committed to the maximization of overall well-being. First, she is committed to the maximization of overall well-being only as a by-product of being committed to the maximization of the well-being of the individuals potentially affected by a particular decision. In other words, she is a global maximizer (like the Consequentialist) only because (unlike the Consequentialist) she has a prior interest in local maximization and the two kinds of maximization happen to coincide. Second, she is a local maximizer only because she subscribes to the principle of respect and additivity and the principle of respect and equality. If she had different principles for weighing individuals' potential benefits and harms, her view would not involve local maximization, and hence not global maximization.

\footnotetext{
${ }^{22}$ Singer, Practical Ethics, p. 14.

${ }^{23}$ See, for example, Katarzyna de Lazari-Radek and Peter Singer, The Point of View of the Universe: Sidgwick and Contemporary Ethics (Oxford, 2014).

${ }^{24}$ Singer, Practical Ethics, p. 293.

${ }^{25}$ Singer, Practical Ethics, p. 294.
} 
These points provide a general overview of the contrast between the argumentative strategies of the Consequentialist and the Respecter. In the remaining sections of this article, I discuss further differences and how they lead to the two strategies' having different strengths and weaknesses.

\section{The 'receptacles' objection}

A major difference between the two strategies pertains to their differing levels of vulnerability to a common objection to act utilitarianism - the objection that act utilitarianism treats people as mere 'receptacles' of well-being. This objection can be stated as follows:

Act utilitarianism prescribes the maximization of overall well-being. But the reason we are to promote any given individual's well-being, according to act utilitarianism, is not that individuals have any moral significance, but that wellbeing has moral significance - it is the good. We are to maximize well-being in order to maximize the good, and individuals just happen to be affected because they are the bearers of well-being. Consequently, act utilitarianism essentially treats individuals as mere receptacles of well-being.

One encounters this objection, or something similar to it, fairly frequently in discussions of act utilitarianism. ${ }^{26}$ (The objection is often stated using the phrase 'receptacles of pleasure', but I use the phrase 'receptacles of well-being' to keep the 'receptacles' objection distinct from debates about the best theory of well-being.)

Let us consider how the Consequentialist and the Respecter can respond to this objection. The Consequentialist's best reply may be to point out that even if the objection accurately describes the way act utilitarians treat individuals, that is a pretty good way to be treated. After all, an individual's well-being, by definition, is everything that makes him or her fare well. (As indicated at the end of the previous paragraph, I assume the objection does not have to do with a particular act utilitarian allegedly having a misguided conception of well-being.) Putting the point more sharply, the Consequentialist might say the following to the objector:

Think of it this way. If there is an act utilitarian running around, and he's trying to maximize overall well-being, and to do this, he's identifying 'receptacles of wellbeing' (as you say), wouldn't you want him to notice you and regard you like that, rather than not like that - for example, as a robot, or a statue, or a corpse? Surely you would, and this shows that that is a pretty good way to be treated.

This reply has some force. But it cannot refute the main thrust of the objection, which is that act utilitarianism advocates the good treatment of individuals not for their own sakes, but for the sake of the larger project of globally maximizing the good. The fact that the Consequentialist regards well-being as the good makes individuals beneficiaries of his acts, but not objects of concern to him - except, again, as receptacles.

\footnotetext{
${ }^{26}$ See, for example, Sen and Williams, 'Introduction', p. 4; Tom Regan, The Case for Animal Rights, rev. edn. (Berkeley, 2004), pp. 205-6, 208-9, 248-50 and 302-3; Martha C. Nussbaum, Creating Capabilities: The Human Development Approach (Cambridge, MA, 2011), p. 160; and Singer, Practical Ethics, p. 106.
} 
The Respecter can give a much stronger reply to the 'receptacles' objection - largely because the objection essentially gets her thinking backward. She does not first aim to maximize overall well-being and then promote individuals' well-being because it serves that purpose. Rather, her first concern is with individuals, and how to decide conflicts between them. Her view of how to decide conflicts results in the maximization of overall well-being, but that is not its basis or rationale. In addition, she can say the following to the objector:

Tell me who you think does not treat individuals as mere receptacles - a Lockean natural-rights theorist? a Kantian deontologist? a Scanlonian contractualist? I don't treat individuals as receptacles any more than they do. Suppose two individuals come to us with some kind of conflict. All of us theorists will accord immediate importance to each individual involved, take the individuals' concerns seriously, weigh them in a morally principled way, and reach a decision. I don't have a larger agenda, looming above the individuals involved in the situation, any more than those non-utilitarians do.

Thus, unlike the Consequentialist, the Respecter can deny the main thrust of the 'receptacles' objection: she can legitimately claim to be concerned with individuals for their own sakes.

The contrast I have just drawn between the Consequentialist's and the Respecter's possible replies to the 'receptacles' objection is reflected, I would argue, in a recent and rich discussion of this objection by Richard Yetter Chappell. ${ }^{27}$ The heart of Chappell's discussion is the contrast between two forms of utilitarianism: tokenmonistic utilitarianism and token-pluralistic utilitarianism. On the monistic view, 'only one token thing, namely aggregate welfare, has intrinsic value'. Thus, 'the tokenmonistic utilitarian mindset involves but a single desire-to maximize welfare-and treats our individual interests and concerns as mere (constitutive) means to the satisfaction of this more global goal'. This, according to Chappell, is 'morally perverse' and vulnerable to the 'receptacles' objection. In contrast, on the pluralistic view,

each person's particular interests are (separately) accorded final value. There is not just one thing, the global happiness, that is good. Instead, there is my happiness, your happiness, Bob's, and Sally's, which are all equally weighty but nonetheless distinct intrinsic goods. What this means is that the morally fitting agent should have a corresponding plurality of non-instrumental desires: for my welfare, yours, Bob's, and Sally's. Tradeoffs between them may be made, but they are acknowledged as genuine tradeoffs: though a benefit to one may outweigh a smaller harm to another, this does not cancel it. The harm remains regrettable, for that person's sake, even if we ultimately have most reason to accept it for the sake of more greatly benefiting another.

Chappell holds that while the monistic view is vulnerable to the 'receptacles' objection, the pluralistic view is not. I agree with this assessment, and only wish to add that the difference between the two views parallels the difference between the Consequentialist and the Respecter. It is easy to see how the monistic view is the kind of view the

\footnotetext{
${ }^{27}$ Richard Yetter Chappell, 'Value Receptacles', Noûs 49 (2015), pp. 322-32. All references to this article are to p. 328.
} 
Consequentialist would hold, since the monistic view's starting point of 'aggregate welfare' (quoted above) is a key link in the chain of reasoning that I presented, above, as defining the Consequentialist. And to see how the pluralistic view exemplifies Respecter-ish reasoning, recall that the Respecter does not first aim to maximize overall well-being and then promote individuals' well-being because it serves that purpose rather, her first concern is with individuals, and how to decide conflicts between them. This line of thinking is exemplified by Chappell's characterization of the tokenpluralistic utilitarian agent as starting from 'my welfare, yours, Bob's, and Sally's', and then engaging in trade-offs as needed. And when are trade-offs needed, on that view? They are needed, I think it is clear, when the agent's desire for (say) Bob's welfare conflicts with the agent's desire for (say) Sally's welfare. This aligns closely with the Respecter's view of morality as being concerned with treating individuals respectfully and deciding conflicts between them, irrespective of any overarching project of globally maximizing anything.

This examination of Chappell's discussion reinforces the main point of this section, which is that the Respecter is much less vulnerable to the 'receptacles' objection than the Consequentialist is. This section also, however, highlights the importance of the Respecter's principle for treating individuals respectfully - a principle that some critics of act utilitarianism will be inclined to reject. I turn to this issue next.

\section{The 'bad account of respect' objection}

The Respecter is vulnerable to an objection that I call the 'bad account of respect' objection. As its name suggests, this objection pertains to the Respecter's principle for treating individuals respectfully. Recall that this principle is the respect and interests principle:

respect and interests: An individual is treated respectfully in the making of a decision that affects him or her if and only if, and to the extent that, the decisionmaking aims at the protection and promotion of his or her interests.

As I mentioned when I introduced this principle, it essentially means that treating individuals respectfully involves attending to their interests.

An objector might assert that this is a bad way to conceptualize treating individuals respectfully. To begin to argue for this assertion, the objector might present several hypothetical situations:

1. Abel and Beth are siblings whose parents are planning to move to another state. Abel loves soccer and might well receive an athletic scholarship to college if he can keep developing his skills; this would require the family's moving to the suburbs, where the best youth soccer leagues are. Beth has unusual medical needs that can be addressed only by the family's moving to the city, where the research hospitals are. Because Beth's condition can be ameliorated only partially, the benefit to her of the family's moving to the city would be less than the benefit to Abel of the family's moving to the suburbs. ${ }^{28}$

2. Adam and Bonita are siblings with similar levels of health and other important goods. With their parents' approval, Bonita has been cleaning and painting a

\footnotetext{
${ }^{28}$ This is based on Thomas Nagel, Mortal Questions (Cambridge, 1979), pp. 123-4.
} 
spare room in their house, with the intent of making it her bedroom. When the work is finished, Adam argues that the room should be his. He points out - correctly, let us assume - that the room would benefit him more than his sister, since she spends little time at home, whereas the opposite is true of him. ${ }^{29}$

3. Andy and Bonnie are co-workers, and are the only candidates for a promotion that comes with a significant raise. Bonnie is more deserving in terms of both seniority and ability, and she would be more competent in the new position than Andy would. But the promotion would benefit Andy much more, since he is the sole breadwinner for a large family whereas Bonnie's kids are grown and self-supporting and her spouse makes plenty of money.

Because of the stipulations about the benefits and harms in these situations, the implications of the respect and interests principle are clear: treating individuals respectfully means giving greater weight to the claims of Abel, Adam and Andy than to the claims of Beth, Bonita and Bonnie. The objector might then articulate the 'bad account of respect' objection in the following way:

The respect and interests principle is a bad account of respect because treating an individual respectfully involves attending to more than just how much the individual stands to be benefited or harmed in that situation. Therefore, the respect and interests principle is radically incomplete. In some cases, such as cases 1-3 above, this inadequacy causes the respect and interests principle to imply incorrect comparative judgments about whose claims should be given greater weight, if we are concerned with treating individuals respectfully. In some other cases, the respect and interests principle might correctly identify which individual has the weightier claim, but it still grounds that judgment in a deplorably incomplete set of relevant factors.

Let us take this as the basic statement of the 'bad account of respect' objection.

Upon stating this objection, it would be natural for the objector to be asked to identify the other factors that are relevant to treating individuals respectfully. In reply, the objector might mention the following: whether one individual is already faring well while another is faring badly (as with Abel and Beth), whether one individual wants to free-ride on the efforts of another (as with Adam and Bonita), and whether one individual is less deserving than another (as with Andy and Bonnie). Going beyond the cases given above, the objector might mention that treating individuals respectfully also involves attending to whether they are at risk of having their rights or dignity violated, whether they have been loyal, and whether they have been law-abiding. But presumably the objector needn't present a particular unassailable alternative to the respect and interests principle in order to mount a prima facie argument that it is woefully lacking.

There may or may not be a good rebuttal for the Respecter to give in response to the 'bad account of respect' objection. Here, I want to focus on how this objection poses a challenge for the Respecter but not for the Consequentialist, since here I am concerned with the differences between these two views more than with the success or failure of either one of them. On this point the Respecter might argue that this objection is

\footnotetext{
${ }^{29}$ This is derived, very loosely, from Sen's story of 'three children and the flute' as presented in Amartya Sen, The Idea of Justice (Cambridge, 2009), pp. 12-15.
} 
just as troublesome for the Consequentialist as for her, since the Consequentialist is committed to issuing all of the same prescriptions as she is in cases such as the ones given above. After all, the Consequentialist is just as much of an act utilitarian as the Respecter is; therefore, he, too, is just as committed to the outcomes preferred by Abel, Adam and Andy, and to denying the moral significance of factors such as rights and loyalty.

This argument, however, rests on a misrepresentation of the 'bad account of respect' objection. That objection is not that act utilitarianism issues implausible all-thingsconsidered moral judgements in cases such as the ones given above. Rather, the objection is that the respect and interests principle issues implausible implications concerning what is involved in treating individuals respectfully in cases such as the ones given above. And the objection is applicable only to the Respecter, because only she (and not the Consequentialist) is committed to an account of what is involved in treating individuals respectfully.

We can see this difference between the Respecter and the Consequentialist more vividly if we notice that it would be open to the Consequentialist (if also a little ungenerous of him) to reply to the foregoing argument from the Respecter in the following way:

You are right that if most people think the act-utilitarian moral judgments in cases such as the ones given above are implausible, then that is a problem for me as much as it is a problem for you. I know it is a problem. But the 'bad account of respect' objection is a separate problem. It's one thing to say (as we both must) that the act-utilitarian judgments in those cases are right. It's another thing to defend that position by saying that treating individuals respectfully means giving greater weight to the claims of Abel, Adam and Andy than to the claims of Beth, Bonita and Bonnie. Frankly, I don't see how you can maintain that. I certainly do not take any stance like that in my version of act utilitarianism. But that is a stance you are stuck with, because of the way you choose to argue for act utilitarianism, by way of the respect and interests principle.

In short, the Respecter's argumentative strategy requires her to take a stand on what is involved in treating individuals respectfully. In contrast, the Consequentialist steers clear of that topic. That is what makes the 'bad account of respect' objection a burden for the Respecter but not for the Consequentialist.

\section{Consequentialism and prudential rationality}

The previous two sections explored how the argumentative strategies of the Consequentialist and the Respecter differ in terms of their vulnerability to serious objections. In this section and the next one, I want to discuss how they differ in terms of distinctive strengths they can assert due to the different relationships they have to the principle of act consequentialism.

Recall the statement of this principle from earlier in this article:

act consequentialism: An act is right if and only if its consequences are at least as good as the consequences of any act the agent could have performed.

Of course, the context in which this principle was stated was the exposition of the defining theses of the Consequentialist. So, the relationship of the Consequentialist to this 
principle is clear and unmistakable: the Consequentialist is, among other things, an act consequentialist.

This attribute enables the Consequentialist to bolster his position by invoking arguments that can be given in support of act consequentialism. Admittedly, proponents of act consequentialism usually need to focus their efforts on responding to objections rather than presenting supporting arguments per se. But one supporting argument that does appear from time to time, and that some people find compelling, is that act consequentialism's goal-oriented and maximizing character makes it resemble what might be regarded as the default normative principle for decision-making in an important non-moral context - the realm of personal goods, or the prudential realm. Philip Pettit presents this argument in the following way:

In thinking about how an agent should act on the concern for a personal good, we unhesitatingly say that of course the rational thing to do, the rationally justified action, is to act so that the good is promoted. That means then that whereas the consequentialist line on how values justify choices is continuous with the standard line on rationality in the pursuit of personal goods, the non-consequentialist line is not. The non-consequentialist has the embarrassment of having to defend a position on what certain values require which is without analogue in the non-moral area of practical rationality. ${ }^{30}$

In short, if maximally promoting the good is rational in prudential contexts, that establishes a presumption in favour of act consequentialism as a principle for moral contexts. It might be a rebuttable presumption, but at the very least, this is an argument for act consequentialism that shifts the burden of proof to opponents of that view. And it is an argument that the Consequentialist can invoke as supporting his argumentative strategy, since act consequentialism is one of its main elements. In contrast, this argument for act consequentialism is of no use to the Respecter, since her argumentative strategy does not include any appeal to that principle.

\section{Non-consequentialism}

It might appear that the Respecter is equally eligible to invoke arguments for act consequentialism to bolster her position, since she joins the Consequentialist in embracing act utilitarianism and that view is often understood to be a form of act consequentialism. Recall, however, that act consequentialism is not part of the chain of ideas that constitute the argumentative strategy of the Respecter. Of course, anyone who accepts the Respecter's ideas is free to accept any of the Consequentialist's ideas (including act consequentialism); there is no incompatibility between their principles. My only point here is that arguments for act consequentialism, such as the prudentialrationality argument considered in the previous section, do not support any of the principles that the Respecter asserts as the basis for her avowal of act utilitarianism.

Given this fact about the Respecter's view, it might appear that the Respecter is stuck in the worst of both worlds, as far as her relationship to act consequentialism is concerned: as an act utilitarian, she appears to be vulnerable to all of the objections that act consequentialism is vulnerable to, but because of her argumentative strategy, arguments in support of act consequentialism do not bolster any of the components of her

\footnotetext{
${ }^{30}$ Pettit, 'Consequentialism', p. 238.
} 
view. In short, it might appear that she has all of the baggage of being an act consequentialist, but none of the benefits.

In my view, however, the Respecter's eschewing of act consequentialism in her argumentative strategy actually affords her a surprising opportunity: the opportunity to disavow consequentialism and frame her view as a form of non-consequentialism. This suggestion might initially sound like a non-starter, given that it is often assumed that any form of utilitarianism is necessarily also a form of consequentialism. ${ }^{31}$ But it turns out that even if a theorist is a utilitarian - even an act utilitarian - he can still position himself as a non-consequentialist in any of several different ways. ${ }^{32}$ (Here, our imagined theorist is not the Respecter or the Consequentialist, but just any old act utilitarian.)

First, he might just decline to affirm any proposition about the right being a matter of promoting the good. For example, he might say the following:

1. I know some theorists believe the good is prior to the right, and using a welfarist conception of the good, they derive act utilitarianism as their view of right and wrong. I agree with their view of the good and their resulting ranking of states of affairs, and I believe right acts produce the best available states of affairs, but I don't believe that is what makes them right. I believe you can do deontic ethics without doing axiology, as illustrated by the way the Respecter argues for act utilitarianism.

Alternatively, he might say the following:

2. I know some theorists believe the good is prior to the right, and using a welfarist conception of the good, they derive act utilitarianism as their view of right and wrong. But I don't believe the good is prior to the right, and I don't even have views about the good. I believe you can do deontic ethics without doing axiology, as illustrated by the way the Respecter argues for act utilitarianism.

Yet a third option is for him to say the following:

3. I don't believe the good is prior to the right, because I don't believe that possible states of affairs can be evaluated relative to each other. I believe there are right and wrong acts, but not better and worse states of affairs.

All three of these stances are forms of non-consequentialism. But one might find them a bit thin; in each case the imagined theorist is committed to non-consequentialism as a

\footnotetext{
${ }^{31}$ This seems to be assumed, for example, in Christopher Miles Coope's suggestion that since Mill was not a consequentialist, he was not a utilitarian. See his 'Was Mill a Utilitarian?', Utilitas 10 (1998), pp. 33-67, at 33 .

${ }^{32}$ The possibility of a non-consequentialist form of act utilitarianism might appear to have been anticipated by Daniel Jacobson, 'Utilitarianism without Consequentialism: The Case of John Stuart Mill', The Philosophical Review 117 (2008), pp. 159-91. But the utilitarianism that Jacobson attributes to Mill is, he admits, 'highly unorthodox' (p. 160 and p. 191); it's a utilitarianism denying that 'everyone's happiness counts in exactly the same way when it comes to evaluating acts as right and wrong' (p. 168; see also p. 178). One might regard this denial as incompatible with utilitarianism, but Jacobson holds that because 'utilitarianism was a movement in the history of ideas ... that appellation must be understood broadly enough to include the views of Bentham and Mill' (p. 164). Jacobson does not claim to show, as I do, that an orthodox form of utilitarianism is not necessarily consequentialist.
} 
matter of method, but he does not use this freedom to associate himself with any substantive positions that are contrary to consequentialism. Let us observe, then, that if the theorist were so inclined, he could assert such positions. For example, he could say the following:

4. Act utilitarianism is my view of right and wrong. I also have a conception of the good; I hold that the good includes not only well-being wherever it may be found, but also pious religious practices and the preservation of the natural environment. Accordingly, I hold that one state of affairs is better than another when it has more of these things, and worse when it has less. Although I have this particular view of the relative values of states of affairs, it does not dictate my view of right and wrong, which (as I said) is act utilitarianism. I think that when a person acts rightly, sometimes the resulting state of affairs is the best one available, and sometimes it is not.

Here our imagined theorist is not just demurring from the principle of act consequentialism; the last sentence actually precludes him from embracing that principle, even if he were so inclined. (Of course, any conception of the good that differs from the maximization of well-being would work equally well in this example.)

This interlude concerning some ways in which an act utilitarian can also be a nonconsequentialist is not meant to suggest that the Respecter ought to be understood as asserting any of views 1-4. Rather, it is just meant to refute the assumption (noted in the third paragraph of this section) that as a utilitarian, the Respecter is necessarily also a consequentialist, and hence debarred from situating herself as a nonconsequentialist. On the contrary, this is a perfectly viable option for her.

How might this option be advantageous for her? Well, the distinction between consequentialism and non-consequentialism is one of the major divides in normative ethics. Non-consequentialists may have their intramural disputes concerning what the best moral theory is, but they have generated a swarm of objections to consequentialist theories having to do with the moral status of persons, the importance of individual rights, and other issues. Regardless of what one thinks of the cogency of these objections, it cannot be denied that they constitute one of the busier lines of fire in normative ethics. Therefore, it is significant that the Respecter has the option of avoiding these criticisms by positioning herself as a non-consequentialist.

This does not mean, of course, that the Respecter will be uncritically embraced by (other) non-consequentialists. They might see her act utilitarianism packaged as a form of non-consequentialism as being little more than a wolf in sheep's clothing. And besides, as just noted, non-consequentialists already disagree among themselves about what the right sort of sheep is. But this latter fact works to the Respecter's advantage, too - there is no single positive doctrine, common to non-consequentialist theories, that can be used to check the Respecter's non-consequentialist bona fides. Just her ability to eschew consequentialism is enough to put her in the non-consequentialist camp. This gives her an important dialectical option that the Consequentialist, obviously, cannot employ.

\section{Conclusion}

The argumentative strategies of the Consequentialist and the Respecter have different strengths and weaknesses. The Consequentialist's strategy is much more vulnerable to 
the 'receptacles' objection but can draw support from its similarity to what is arguably the default normative principle for decision-making in the prudential realm - the principle of maximally advancing one's aims. In contrast, the Respecter's strategy relies on a controversial principle for treating individuals respectfully but leaves room for her entire view to be characterized as a form of non-consequentialism, thereby avoiding one of the main traditional lines of criticism of act utilitarianism.

It would be premature to identify one of these strategies as clearly superior to the other. The true force of each of the considerations just mentioned will be most clearly revealed in the earnest articulation of - and subsequent debate over - forms of act utilitarianism that avow and develop these strategies. More importantly, greater attention to these strategies as distinct options for justifying act utilitarianism may foster progress in the development of justifications of act utilitarianism, whether in the form of one of these two strategies or other possibilities not contemplated here. (Or, greater attention to these strategies may contribute to a consensus that any justification of act utilitarianism is bound to be highly problematic.) In the meantime, greater attention to these strategies might lead act-utilitarian writers to identify the bases of their views more explicitly, so that their readers can be more cognizant of the justificatory principles they are being invited to affirm. ${ }^{33}$

\footnotetext{
${ }^{33}$ I would like to thank Dale Miller, two anonymous referees, and my colleagues at the University of Kansas for helpful comments on, and discussion of, an earlier version of this article.
}

Cite this article: Eggleston B (2019). Consequentialism and Respect: Two Strategies for Justifying Act Utilitarianism. Utilitas 1-18. https://doi.org/10.1017/S0953820819000086 